\title{
Therapeutic Hemin
}

National Cancer Institute

\section{Source}

National Cancer Institute. Therapeutic Hemin. NCI Thesaurus. Code C68925.

A sterile, lyophilized powder of hemin, the $\mathrm{Fe} 3+$ oxidation product of heme $(\mathrm{Fe} 2+)$, derived from processed red blood cells. Therapeutic hemin appears to inhibit delta-aminolevulinic acid (ALA) synthetase, a rate-limiting enzyme in the porphyrin/heme biosynthetic pathway, resulting in inhibition of the hepatic and/or marrow synthesis of porphyrin precursors. The mechanism by which therapeutic hematin produces symptomatic improvement in patients with acute episodes of the hepatic porphyrias has not been determined. 